REVISTA ANDALUZA DE ANTROPOLOGÍA.

NÚMERO 2: PATRIMONIO CULTURAL Y DERECHOS COLECTIVOS.

MARZO DE 2012

ISSN 2174-6796

[pp. 108-127]

http://dx.doi.org/10.12795/RAA.2012.i02.06

\title{
LA ANTROPOLOGIZACIÓN DEL PATRIMONIO Y LA PATRIMONIALIZACIÓN DE LA CULTURA. DOCUMENTAR EL PATRIMONIO ETNOLÓGICO EN EL IAPH
}

\section{GEMA CARRERA DÍAZ}

Instituto Andaluz del Patrimonio Histórico. Grupo de investigación GEISA.

ANICETO DELGADO MÉNDEZ

Instituto Andaluz del Patrimonio Histórico.

\section{Resumen.}

Se pretende contextualizar la aparición de profesionales de la antropología en el IAPH paralelamente a una serie de cambios sociales, académicos y políticos que se dieron en Andalucía al principio de los años 90 y que se plasman en una ampliación del concepto de patrimonio cultural. Se reflexionará acerca de la evolución de la antropología en esta institución, la situación actual de la profesión y la gestión patrimonial en el IAPH.

Palabras clave: Patrimonio cultural, antropología, gestión del patrimonio, Andalucía.

\section{Abastract.}

The article seeks to contextualize the hiring of professional anthropologists by the IAPH (Instituto Andaluz del Patrimonio Histórico, in Spanish) within a set of social, academic 
and political changes in Andalusia at the beginning of the nineties of the last century. Those changes led to an enlargement of the concept of cultural heritage. It reflects about the evolution of anthropology within the IAPH, the current situation of the profession, and the heritage management by this institution.

Keywords: Cultural heritage, anthropology, heritage management, Andalusia.

\section{INTRODUCCIÓN}

Una de las instituciones de la administración autonómica andaluza, que de forma más temprana incorporó la antropología como disciplina de su equipo de especialistas, fue el Instituto Andaluz del Patrimonio Histórico. El Patrimonio Etnológico en nuestra comunidad tuvo, en los primeros años 90 del siglo XX un tratamiento pionero en su primera ley de patrimonio Histórico (ley 1/91 de Patrimonio Histórico de Andalucía), gracias a la conjunción de varios factores: uno relacionado con las políticas culturales que nacen bajo el auspicio del Estatuto de Autonomía, otro relacionado con los estudios académicos de Antropología sobre la cultura e identidad andaluza en la Universidad de Sevilla, que permiten la incorporación de esta disciplina a la construcción de un concepto mucho más amplio de patrimonio cultural y, por último, la necesidad de dar respuesta a movimientos sociales que reivindicaban una mayor representación a través de sus expresiones culturales.

Entre los instrumentos que la Consejería de Cultura generó, en consonancia con los principios estatutario ${ }^{1}$, para afianzar la identidad cultural andaluza y respondiendo a las definiciones de patrimonio cultural más avanzadas según los postulados que la UNESCO estaba defendiendo en aquellos momentos, se encuentra la Ley 1/1991, de Patrimonio Histórico de Andalucía. En ella se reconoce como parte del patrimonio cultural de Andalucía (el denominado patrimonio etnológico), los "lugares, bienes, o actividades que alberguen o constituyan formas relevantes de expresión de la cultura y modos de vida propios del pueblo andaluz". Se incorpora así a nuestro concepto de patrimonio un enfoque integral y moderno que abarca tanto lo material como lo inmaterial, las herencias del pasado como las realidades contemporáneas. Su interés viene determinado, no tanto por su singularidad o excepcionalidad, sino por su función social o su valor simbólico.

1. "afianzar la conciencia de identidad andaluza, a través de la investigación, difusión y conocimiento de los valores históricos, culturales y lingüísticos del pueblo andaluz en toda su riqueza y diversidad" (art.12.3); y uno de los medios para lograr este objetivo es el que ordena en el artículo 19.2 "los poderes de la Comunidad Autónoma velarán porque los contenido de la enseñanza e investigación en Andalucía guarden una esencial conexión con las realidades, tradiciones, problemas y necesidades del pueblo andaluz". 
Otro instrumento fundamental que se desarrolló en aquel contexto fue el I Plan General de Bienes Culturales 1989-95 (1993), que recuerda el mandato estatutario de afianzamiento de la identidad de los andaluces y señala como uno de sus objetivos, el de la "la divulgación del Patrimonio como instrumento para la identificación de la sociedad andaluza con su propia cultura, teniendo en cuenta que la consideración de ese patrimonio como señas de identidad de una colectividad es el medio más eficaz de protección y defensa" (Junta de Andalucía 1993: 61).

Este Plan General tendría entre sus cometidos la creación del Instituto Andaluz del Patrimonio Histórico. Desde su creación por el Decreto 107/1989, de 16 de mayo, esta institución ha venido ejerciendo, de acuerdo con sus artículos 1 y 2, actuaciones en materia de protección, investigación, difusión, conservación y restauración del patrimonio histórico y sus instituciones y ha contado, para ello, con un equipo multidisciplinar. Se gestaba entonces, la creación, en el Centro de Documentación, del Sistema de Información del Patrimonio Histórico de Andalucía (SIPHA), que casi desde sus inicios, contó con una perspectiva antropológica para la documentación del patrimonio inmueble de Andalucía y las actividades que estos albergaran.

No menos importantes que estas políticas culturales, y muy relacionadas con su evolución, fueron los estudios que en el ámbito académico se han venido llevando a cabo en el departamento de Antropología Social de la Universidad de Sevilla y otras universidades andaluzas, que contribuyeron a la construcción de un concepto de patrimonio cultural mucho más amplio, menos elitista y representativo de la identidad cultural andaluza ${ }^{2}$.

Por supuesto, ha contribuido también, en gran medida, a la incorporación del concepto antropológico de cultura en el ámbito del patrimonio cultural, la necesidad

2. Ejemplo de todo ello es la producción científica de muchos de los componentes del Grupo para el Estudio de las Identidades Socioculturales en Andalucía (GEISA), del Departamento de Antropología Social de la Universidad de Sevilla, dirigido por Isidoro Moreno Navarro, destacando la labor de su propio director en el estudio de la cultura y la identidad andaluzas, ocupándose sobre todo de la dimensión simbólica de los fenómenos sociales contemporáneos en la dialéctica que comportan la globalización y la reafirmación de las identidades (localización). Destaca el papel de Juan Agudo Torrico, en la línea de investigación de Patrimonio Etnológico, sobre todo en el ámbito de los rituales festivos y la arquitectura vernácula, o la de Esther Fernández de Paz en el estudio de los oficios y saberes artesanos en Andalucía. No han sido menos importantes, por lo que han aportado a los estudios de etnicidad en Andalucía, algunos de los trabajos que han realizado a lo largo de su trayectoria miembros de otros grupos de investigación como el Grupo de Investigación Social y Acción Participativa (GISAP) del Departamento de Trabajo Social y Servicios Sociales (UPO), dirigido por Javier Escalera Reyes; el Grupo Patrimonio Etnológico Recursos Socio-Económicos y Simbolismo (PERSES), del Departamento de Antropología Social de la Universidad de Sevilla, dirigido por Encarnación Aguilar Criado; el Grupo Etnografía y Mediaciones de Comunicación y Desarrollo (Etnomedia-CD), del Departamento de Antropología Social de la Universidad de Sevilla, dirigido por Antonio Mandly; el Grupo de Investigación y Estudios sobre la Religión de los Andaluces, dirigido por Salvador Rodríguez Becerra (Departamento de Antropología Social de la Universidad de Sevilla); o el Laboratorio de Antropología de la Universidad de Granada. (Carrera, 2009a) 
de dar respuesta, a las reivindicaciones sociales de muchos colectivos andaluces que solicitaban una mayor representación institucional de sus propias expresiones culturales, y las respuestas que a ello se han dado mediante la inscripción en el Catálogo General del Patrimonio Histórico de Andalucía. Ejemplo de ello son algunos expedientes emblemáticos como la Huerta Noble (Isla Cristina); la Huerta de Pegalajar, como un sistema complejo económico, social y cultural, asimilable al concepto de paisaje cultural que abarca ciudad y terrenos de cultivo; el Corral de la Encarnación (Sevilla); la Fábrica de Vidrio de la Trinidad (Sevilla); el Corral de San José (Sevilla); La Casa Palacio del Pumarejo (Sevilla); Las carpinterías de Ribera de Coria del Río (Sevilla) o de Pedregalejo (Málaga); o las más recientes Danzas rituales de la Provincia de Huelva, Cabalgata de Reyes de Higuera de la Sierra (Huelva); o las Fiesta de Verdiales (Málaga); etc.

Las reivindicaciones sociales que representan muchos de estos expedientes, no han tenido siempre, o casi nunca, soluciones completamente satisfactorias, no por falta de voluntad sino, porque son gigantes los molinos con los que se enfrentan dichos grupos sociales y las herramientas jurídicas que emplean para intentar "proteger" parte de sus vidas (espacios, oficios u otras expresiones culturales): gerentrización de los centros históricos, recalificaciones de suelo, sobreexplotación de acuíferos, especulaciones urbanísticas, transformaciones socioecocómicas... No obstante, ha sido importante la labor que la etnología ha desempeñado a su favor desde el departamento de protección de la Dirección General de Bienes Culturales.

La propia idiosincrasia del patrimonio etnológico, entre otros factores, dificulta poder llevar a término lo que en el nivel teórico ya se ha alcanzado. Ello se debe a que los elementos patrimoniales de carácter etnológico son de naturaleza opuesta al concepto tradicional de patrimonio histórico artístico. No son singulares, ni escasos, ni son importantes por sus valores artísticos, sino por sus significados socioculturales; aunque se apoyen en la tradición, son bienes vivos, y por lo tanto se transforman y usan cotidianamente. Además de sus propias características como patrimonio vivo, de la deuda histórica que tiene la sociedad y la tutela patrimonial en la valorización de este patrimonio, y de las dificultades para gestionar lo inmaterial y la identidad, existen otras causas que afectan directamente a este patrimonio vivo: los procesos de globalización y la aceleración de las transformaciones sociales actuales, comportan riesgos de deterioro, desaparición y destrucción de los valores inmateriales del patrimonio cultural y sobre todo del patrimonio etnológico.

\section{EVOLUCIÓN DE LA DOCUMENTACIÓN DEL PATRIMONIO ETNOLÓGICO EN EL IAPH: DE LA ARQUITECTURA VERNÁCULA AL PATRIMONIO INMATERIAL.}

La profesionalización de la antropología fuera del ámbito académico tiene, pues, entre otras áreas de actuación el patrimonio cultural. La antropología ha desempeñado un 
papel muy importante en este sentido en diferentes instituciones andaluzas, entre ellas, el IAPH. Fundamentalmente, la labor de antropólogas y antropólogos en este entidad de carácter científico, adscrita a la consejería de cultura, se realiza en el Centro de Documentación y Estudios.

Desde 1991 y respondiendo a las competencias otorgadas por el I Plan General del Bienes Culturales al Centro de Documentación del IAPH, se ha venido desarrollando el Sistema de Información del Patrimonio Histórico de Andalucía (SIPHA). Este sistema se concibió como un instrumento para mejorar el conocimiento del patrimonio cultural y que resultase útil para las funciones de la tutela, para la investigación y para la ciudadanía en general, así como para las políticas de ordenación territorial y medioambiental... En su complejo proceso de elaboración han participado especialistas en Arqueología, Historia del Arte, Arquitectura, Geografía y Antropología, además de expertos en técnicas gráficas, documentalistas y expertos en normalización lingüística.

La información del patrimonio inmueble de carácter etnológico contenido en este sistema en 2010 es de 4.743 registros. A pesar de que se trata de un patrimonio muy extendido por toda la región, pues está relacionado con la cotidianeidad (doméstica, productiva, y modos de sociabilidad), existen relativamente pocos registros, debido a la tardía incorporación del patrimonio etnológico en el ámbito de la tutela y a la escasez de inventarios realizados. No obstante, su presencia ha roto con varias tendencias: frente a bienes fundamentalmente ubicados en las capitales, los inmuebles etnológicos se recogieron, sobre todo, en núcleos rurales; el $90 \%$ son de la edad contemporánea frente a la preeminencia de bienes de la edad moderna o anteriores, ligados a las tipologías constructivas relacionadas con las élites políticas, nobiliarias, eclesiásticas o militares; frente a la superioridad de edificios religiosos o militares, la mayor parte de los inmuebles con valores etnológicos, son edificios productivos (industriales o agropecuarios) o residenciales (viviendas de gran propietario, mediano propietario, pequeño propietario o jornaleros) de diferentes comarcas andaluzas. En el caso de las viviendas, los aspectos constructivos (materiales, elementos sustentantes, cubiertas, elementos ornamentales, etc.) así como sus aspectos funcionales responden a la diversidad de características ecológicas y socioeconómicas de los territorios en los que se han construido y a la diferente estructura de la propiedad de los grupos que las habitan. (Carrera, Mondéjar y Soro, 2007):

En cuanto a las fuentes de información más importantes que se incluyen en el sistema, se encuentran:

- El Inventario de arquitectura popular de Andalucía (Dirección General de Bienes Culturales de la Consejería de Cultura, 1993-1997), que supone el 68\% de la información, con un total de 3.353 bienes registrados. Sus objetivos eran conocer, proteger y difundir los valores de la arquitectura vernácula andaluza, en su doble dimensión material e 
inmaterial. (Agudo Torrico, 1999)

- El Inventario de cortijos, haciendas y lagares (Consejería de Vivienda y Ordenación del Territorio), supone el 17\% de los inmuebles, con 791 registros pertenecientes a Granada, Córdoba, Almería, Cádiz y Málaga.

- El Catálogo General de Patrimonio Histórico de Andalucía que representa el 11\% con 512 bienes protegidos.

La distribución territorial de inmuebles etnológicos, no responde a la mayor o menor presencia de edificios con valores etnológicos en Andalucía, sino a los criterios seguidos por los inventarios citados.

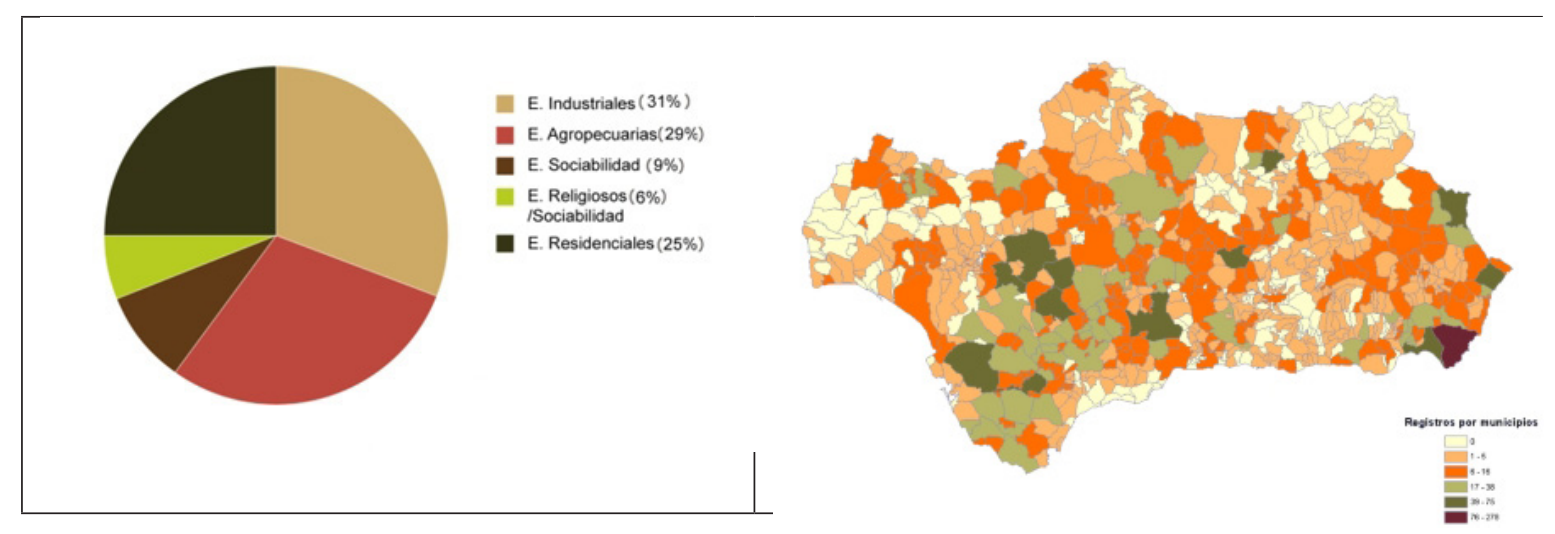

Los bienes inmuebles con valores etnológicos aportan una gran variedad de tipologías funcionales ligadas a los diferentes grupos sociales de la estructura socioeconómica andaluza:

- Edificios productivos representan el 56\%

- Edificios agropecuarios (1.170) e industriales (1.273)

- Edificios residenciales suponen el 25\%

- Espacios de sociabilidad que representan un 9\% entre edificios dotacionales (fuentes, cementerios, lavaderos) y de servicios (panaderías, bares, casinos, tiendas)

- Edificios religiosos suponen un 6\%. Su registro en el sistema responde más a su importancia como referentes simbólicos en el marco de rituales festivos que a las características arquitectónicas o estilísticas de los mismos. 
En general, la incorporación de un enfoque antropológico a la documentación del patrimonio inmueble en el IAPH ha supuesto el reconocimiento de la relación dialéctica entre los elementos patrimoniales y su entorno, así como entre estos y los colectivos que lo han producido a lo largo del tiempo y para los cuales estos espacios tienen significados, funciones y valores simbólicos. Esta visión contextual e identitaria desembocaría más tarde en la importancia del concepto de Paisaje cultural en los estudios del Centro de Documentación del IAPH (Laboratorio del Paisaje) o en los trabajos realizados a partir del concepto de itinerarios culturales.

El holismo propio de la antropología aplicado al patrimonio hace que se incorpore una visión integrada de los bienes patrimoniales donde lo material y lo inmaterial constituyen atributos de todos los bienes patrimoniales, sean inmuebles, muebles o actividades. Por otro lado, ha supuesto en muchos casos la insistencia en la coordinación de actuaciones entre distintas agentes (diferentes consejerías, Universidad, administración Local, etc.).

Otra de las líneas en las que, desde una perspectiva antropológica, se ha venido trabajando en el Centro de Documentación y Estudios del IAPH es en la documentación, valorización y salvaguarda del patrimonio inmaterial.

La UNESCO ha individualizado y consolidado el concepto de "patrimonio inmaterial" con la Convención para la Salvaguardia del Patrimonio Cultural Inmaterial (París, 17 de octubre de 2003), reconociendo la importancia que reviste este patrimonio, crisol de la diversidad cultural y garante del desarrollo sostenible. Algo que ya se había destacado en anteriores documentos como por ejemplo, la Recomendación de la UNESCO sobre la salvaguardia de la cultura tradicional y popular de 1989, la Declaración Universal de la UNESCO sobre la Diversidad Cultural de 2001 o la Declaración de Estambul de 2002.

Como cualquier construcción social, el concepto de patrimonio cultural, es dinámico y refleja los cambios sociales, políticos y económicos de las sociedades que lo producen o definen. El concepto de patrimonio inmaterial contribuye a construir una visión más plural del patrimonio cultural, ampliando el abanico de colectivos sociales representados, más allá del vinculado a las elites sociales dominantes de la sociedad occidental.

El patrimonio cultural inmaterial lo constituyen los "usos, representaciones, expresiones, conocimientos y técnicas -junto con los instrumentos, objetos, artefactos y espacios culturales que les son inherentes- que las comunidades, los grupos y en algunos casos los individuos reconozcan como parte integrante de su patrimonio cultural. Este patrimonio cultural inmaterial, que se transmite de generación en generación, es recreado constantemente por las comunidades y grupos en función de su entorno, su interacción con la naturaleza y su historia, infundiéndoles un sentimiento de identidad y continuidad y contribuyendo así a promover el respeto de la diversidad cultural y la creatividad humana" (art 2.1. UNESCO: Convención para la Salvaguardia del Patrimonio Inmaterial, París 2003) 
La definición de patrimonio cultural inmaterial de la Convención es, en definitiva, la "cultura" en sentido antropológico, reconocida en un orden normativo con rango de Tratado Internacional, que debe servir como instrumento útil para tutelar la diversidad cultural de la humanidad. Esta Convención fue ratificada por España el 25 de octubre de 2006, seis meses después de su entrada en vigor (25-04-06). En ella se entiende por "salvaguardia": "las medidas encaminadas a garantizar la viabilidad del patrimonio cultural inmaterial, comprendidas la identificación, documentación, investigación, preservación, protección, promoción, valorización, transmisión - básicamente a través de la enseñanza formal y no formal- y revitalización de este patrimonio en sus distintos aspectos".

Entre las medidas de salvaguardia más importantes se encuentran las de identificación, conocimiento, investigación valorización y capacitación técnica e institucional (art.12, 13); educación, sensibilización y fortalecimiento de capacidades (art. 14) y participación de las comunidades, grupos e individuos (art.15).

En Andalucía, la legislación vigente, posterior a la ratificación de la convención (Ley 14/2007, de 26 de noviembre, del Patrimonio Histórico de Andalucía) emplea el término y figura de protección Actividad de Interés etnológico para referirse a este tipo de patrimonio cultural dentro del Título VI dedicado al Patrimonio Etnológico. Sin embargo, la presencia de este patrimonio cultural en el Catálogo General del Patrimonio Histórico es aún muy escasa.

El Instituto Andaluz del Patrimonio Histórico aplica este concepto amplio e integrador de patrimonio inmaterial así como el concepto de salvaguarda que defiende la UNESCO a través del proyecto del Atlas del Patrimonio Inmaterial de Andalucía. Una de las mayores virtudes del Atlas del patrimonio inmaterial de Andalucía, y quizás su mayor dificultad, es la de ser un proyecto permanentemente inacabado y vivo, como vivo y dinámico es el patrimonio cultural que a través de él se identifica, documenta, analiza y salvaguarda. Su mayor virtud es que permite visibilizar y amplificar las voces diversas de miles de colectivos y personas, antes invisibilizados y escasamente representados por nuestro patrimonio. El valor de este patrimonio no radica en la excelencia de genios creativos individuales que crean piezas irrepetibles, ni en su singularidad ni en su antigüedad (aunque puede tener todos estos valores). Su valor radica en representar y ser reflejo de la identidad de los colectivos que lo mantienen vivo a lo largo del tiempo adaptándose a él, no con el objeto de convertirlo en espectáculos, sino por la necesidad que tienen los grupos de reproducirse, no solo biológica y económicamente, sino también simbólicamente, heredando saberes y transmitiéndolos o compartiendo espacios públicos, objetos, alimentos, música, juegos, leyendas, bailes, etc. a los que otorgan valor social y simbólico que les permite sentirse miembros de una comunidad. (Carrera Díaz, 2009a y 2009b)

Los rituales festivos, su organización y celebración cíclica, los oficios y saberes, la 
tradición oral y los complejos conocimientos que ellos conllevan, son una forma de resistencia a los efectos homogeneizadores de la globalización. Muchos de los saberes y oficios documentados (dehesa, las salinas, la pesca artesanal, la ganadería extensiva, el mantenimiento de cultivos tradicionales, etc.), permiten la permanencia de muchos ecosistemas andaluces y son absolutamente necesarios para promover un desarrollo económico, ambiental y socialmente sostenible. Por ello, analizamos minuciosamente como se desarrollan y qué problemas les afecta.

Desde que en 2009 comenzara el registro, se han entrevistado a más de 4.200 informantes de 400 municipios andaluces, recorriéndose para ello 400.000 kilómetros del territorio andaluz. Durante el proceso, se han generado más de 20.000 fotografías, 1.400 registros audiovisuales y 600 archivos sonoros.

El ámbito territorial de actuación es todo el territorio de la Comunidad Autónoma Andaluza compuesta por ocho provincias y 771 municipios agrupados en 62 entidades supramunicipales o comarcas que se estudian a lo largo de tres fases anuales en las que se ha programado el registro inicial del patrimonio cultural inmaterial de Andalucía. Esta zonificación es una base de partida para la selección de una unidad territorial lógica y coherente, a partir de unas características territoriales y una trayectoria histórica relativamente homogénea, que las ha definido a lo largo de la historia hasta su configuración actual en la articulación del territorio andaluz.

En el Atlas del Patrimonio Inmaterial de Andalucía se trabaja el patrimonio cultural de manera integrada y holística. Aunque para facilitar su estudio se ha realizado una clasificación inicial en cuatro grandes ámbitos o categorías que permiten generar modelos descriptivos y analíticos adaptados a temáticas muy diferentes (Rituales festivos, oficios y saberes, modos de expresión, alimentación y cocinas). Uno de los objetivos de este proyecto es desarrollar instrumentos de gestión, teóricos y metodológicos específicos para el registro y reconocimiento de estas expresiones culturales elaborando y poniendo a prueba una metodología de registro que podrá ser aplicada permanentemente a diferentes escalas. El registro del patrimonio inmaterial debe hacerse con un criterio territorial, extensivo, valorativo y abierto.

Actualmente se han identificado 1.435 elementos del patrimonio cultural inmaterial de Andalucía:

\footnotetext{
Rituales festivos: 656 rituales festivos representan diferentes tipologías distribuidos a lo largo del ciclo anual, siendo muy comunes en nuestra región las Cabalgatas de Reyes Magos, las Candelarias, carnavales, Romerías, Cruces de Mayo, Ferias, Semana Santa, Corpus Christi, Santos Inocentes. Las fiestas de Moros y Cristianos se extienden fundamentalmente por Andalucía Oriental.
} 
- Oficios y saberes: 406 oficios y saberes han sido identificados y analizados en toda Andalucía, relacionados con:

- Actividades agropecuarias y pesqueras (apicultura, ganadería extensiva, viticultura, olivicultura, huerta, dehesa, descorche, pastoreo, esquileo, arriería, recogida y recolección de frutos (verdeo, castaña); artes de pesca fluvial y marítimas; salinas...)

- Producción agroalimentaria (producción de aceite, vinicultura, panadería, repostería, producción de queso, aguardientes, embutidos, producción de mosto, pasas, apicultura y producción de miel, actividad salinera, mantecados...);

- Actividades de transformación a partir de diferentes materias primas de tipo vegetal, mineral o animal (alfarería, cerámica; carboneo, producción de jabón artesanal; forja, herrería, hojalatería, platería, fabricación de carabinas, jaulas, campanas, cuchillos, romanas, cencerros; espartería, cestería, albardonería, rizado de palma, trabajo de la enea; oficios para la producción de material de construcción: producción de cal, ladrillos, tejas, yeso, losa hidráulica, cantería y técnicas constructivas ( piedra seca); curtiduría, guarnicionería, elaboración de calzado; elaboración de alfombras encajes de bolillos, bordados, costura; carpintería, ebanistería, imaginería, elaboración de rostrillos, fabricación de colmenas, construcción de instrumentos musicales (guitarras, tambores, gaitas, panderos, flautas), tonelería.

- Modos de Expresión: dentro de este ámbito, se registran, expresiones orales, particularidades lingüísticas, memoria e historia oral, representaciones y escenificaciones, bailes, manifestaciones musicales y dancísticas, (incluido el flamenco), transmitidas fundamentalmente de forma oral. De este ámbito temático y hasta la fecha, se han registrado alrededor de 195 expresiones en las zonas estudiadas. Muchos de los contextos de trabajo en los que se cantaba, bailaban y transmitían parte de estas expresiones ya han desaparecido (cantes de trilla, cantes de aceituneros, cantes de mina, etc.), por lo que la mayor parte de los registrados se dan en el marco de los rituales festivos o forman parte de la memoria de las personas encuestadas (juegos, cuentos, leyendas, etc.).

\footnotetext{
Alimentación/Cocina: Se han registrado 180 elementos dentro de este ámbito temático relacionado con actividades y elementos culinarios de elaboración y consumo colectivo que en la mayoría de los casos se encuentran asociados a las actividades festivas o productivas identificadas.
} 


\begin{tabular}{|c|l|l|l|l|l|l|}
\hline PROVINCIA & $\begin{array}{l}\text { R I T U A L E S } \\
\text { FESTIVOS }\end{array}$ & $\begin{array}{l}\text { OFICIOS } \\
\text { SABERES }\end{array}$ & $\begin{array}{l}\text { MODOS DE } \\
\text { EXPRESIÓN }\end{array}$ & $\begin{array}{l}\text { ALIMENTACIÓN } \\
\text { Y COCINAS }\end{array}$ & $\begin{array}{l}\text { TOTALES } \\
\text { POR ÁMBITOS }\end{array}$ \\
\hline ALMERÍA & 69 & 34 & 14 & 16 & 133 \\
\hline CÁDIZ & 50 & 25 & 13 & 7 & 95 \\
\hline CÓRDOBA & 75 & 57 & 21 & 21 & 174 \\
\hline GRANADA & 119 & 68 & 33 & 39 & 259 \\
\hline HUELVA & 72 & 50 & 19 & 16 & 157 \\
\hline JAÉN & 50 & 40 & 15 & 19 & 124 \\
\hline MÁLAGA & 111 & 53 & 31 & 16 & 211 \\
\hline SEVILLA & 110 & 79 & 49 & 44 & 282 \\
\hline $\begin{array}{c}\text { TOTALES } \\
\text { POR }\end{array}$ & 656 & & & & 1435 \\
PROVINCIAS & & 406 & 195 & 178 & \\
\hline
\end{tabular}
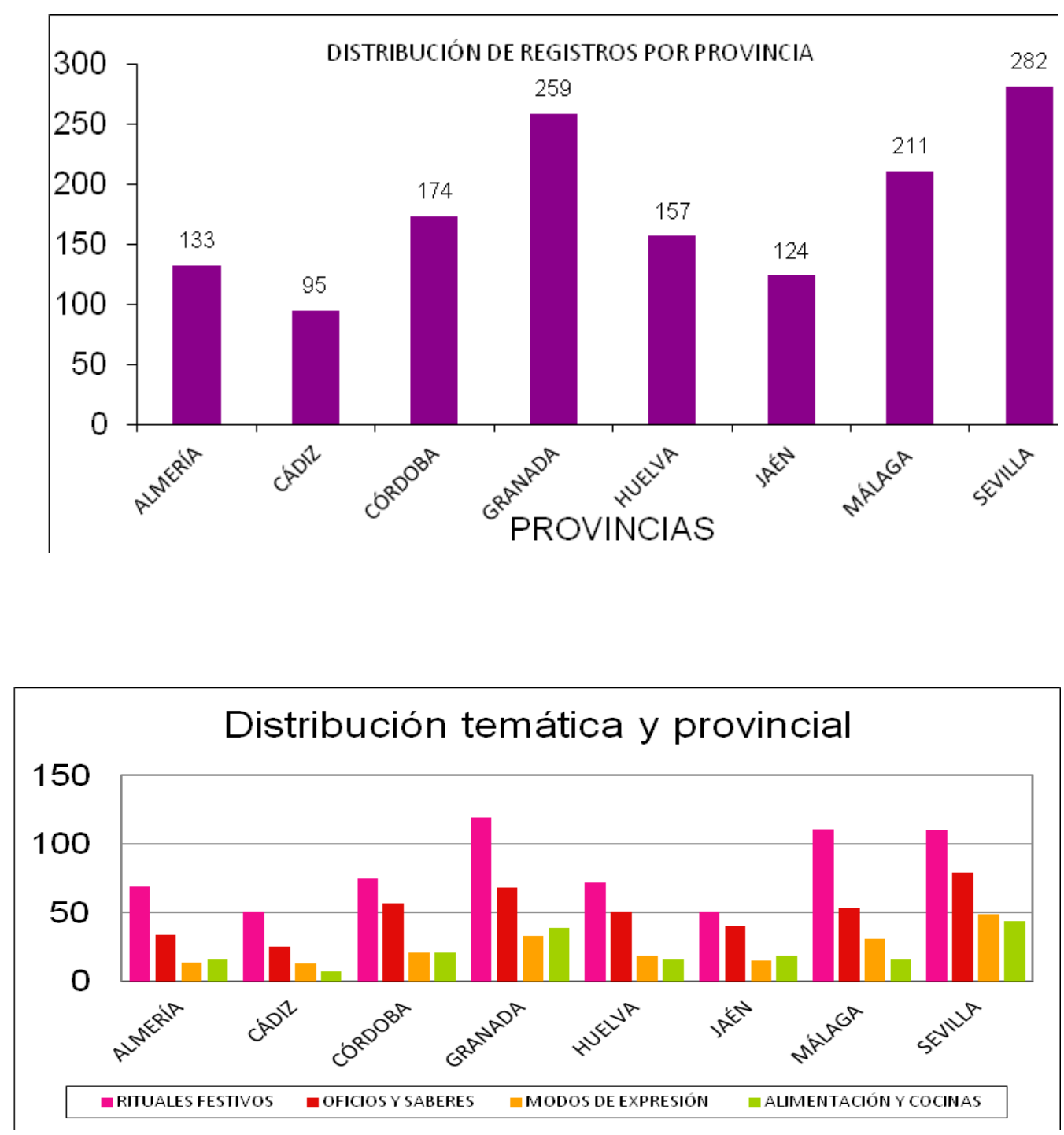
Debido a la envergadura de la obra y a la necesidad de coordinar esfuerzos, el IAPH cuenta con la colaboración, cada vez más amplia de otras instituciones interesadas en el conocimiento y salvaguardia del patrimonio inmaterial: Instituto Andaluz del Flamenco, Centro de Estudios Andaluces, Instituto de Patrimonio Cultural Español, Dirección General de Bienes Culturales, Grupos de Desarrollo Rural de Andalucía, Consejería de Agricultura y Pesca, universidades andaluzas, y, fundamentalmente, informantes y protagonistas del patrimonio inmaterial identificado.

El Atlas incorpora la Red de Informantes y Registradores del Patrimonio Inmaterial de Andalucía, tratando de lograr una participación lo más amplia posible delas comunidades, los grupos y, si procede, los individuos que crean, mantienen y transmiten ese patrimonio y de asociarlos activamente a la gestión del mismo. En esta línea, la sociedad civil, asociaciones y Grupos de Desarrollo Rural, participan activamente en las actividades de documentación y salvaguardia del patrimonio inmaterial de sus territorios.

El proyecto cuenta con una vertiente audiovisual muy importante al tratarse de expresiones vivas y dinámicas para las que el registro en video constituye una de las mejores fórmulas para documentar y difundir estas manifestaciones culturales, además de para diversificar la idea que se ha transmitido tradicionalmente sobre "lo andaluz" en los medios de comunicación de masas. En este sentido, el Atlas puede contribuir a reconstruir una imagen perdida de la diversidad cultural que caracteriza a Andalucía y de los elementos que la cohesionan.

\section{LA IMPORTANCIA DEL REGISTRO GRÁFICO Y SONORO EN LA DOCUMENTACIÓN DEL PATRIMONIO INMATERIAL}

En el proceso de elaboración y desarrollo del proyecto del Atlas del Patrimonio Inmaterial de Andalucía, el análisis y definición de criterios metodológicos encaminados a la documentación audiovisual de los bienes registrados ha constituido una parte importante del mismo.

La necesidad de establecer unos parámetros técnicos que permitan a los equipos de trabajo documentar y gestionar la información audiovisual relacionada con los registros inventariados, así como el conocimiento de las técnicas y medios utilizados, fue un objetivo fundamental desde el punto de vista metodológico.

La puesta en marcha del trabajo de campo, puso de manifiesto desde el principio, las dificultades derivadas de la documentación audiovisual del patrimonio inmaterial y su posterior gestión. La diversidad de elementos inventariados, la especificidad de los mismos y el desconocimiento previo de las herramientas empleadas, han constituido un continuo obstáculo.

Para paliar ciertas carencias en el conocimiento de estas cuestiones se han realizado cursos 
de capacitación y talleres formativos en estas materias con el objetivo de entrelazar los objetivos del proyecto con los criterios del Instituto Andaluz del Patrimonio Histórico de Andalucía en materia de captura, tratamiento y gestión del material audiovisual.

El registro de expresiones de patrimonio inmaterial, ha contado entre otros aspectos, con la elaboración de una ficha específica para cada uno de los ámbitos de trabajo (rituales festivos, oficios y saberes, modos de expresión y alimentación). Junto a esta ficha específica, cada registro va acompañado de información relativa al contexto territorial dentro del cual se circunscriben, y material audiovisual en distintos formatos.

Teniendo en cuenta la especificidad del patrimonio inmaterial y las necesidades de documentación implícitas en el proyecto, la importancia y la atención prestada al registro audiovisual, lo ha convertido en un aspecto clave a la hora de comprender los bienes inventariados y la definición de propuestas de salvaguarda.

Durante el trabajo de campo, los equipos han recogido material en diversos soportes, siendo la fotografía, el video, el registro sonoro y la digitalización, los principales medios de documentación audiovisual.

El procedimiento seguido respecto a la documentación audiovisual, ha sido igual para cada uno de los soportes elegidos. Esto ha permitido homogeneizar el modelo de datos, el trabajo realizado y los resultados obtenidos. Dicho procedimiento podría ser resumido en captura, visualización y selección, metadataje, revelado, documentación y relación con los bienes.

La captura, sea cual sea el soporte, se convierte en el primer paso a la hora de documentar audiovisualmente un registro. Para ello, el uso y conocimiento de la herramienta (cámara de video, cámara de fotos, grabadora, etc.), las condiciones de cada contexto y la elección del medio adecuado se convierten en aspectos claves. Dependiendo de las circunstancias que rodean al registro seleccionado, deberemos optar por el uso de una herramienta $\mathrm{u}$ otra (cámara fotográfica, cámara de video, grabadora de sonido)

La fotografía digital ha sido el medio más utilizado en el trabajo decampo. Los formatos y características técnicas de las imágenes realizadas, han seguido los estándares de calidad establecidos para la documentación gráfica digital del patrimonio cultural por el Área de Técnicas de Documentación Gráfica del IAPH.

La metodología aplicada por este área para generar y validar la documentación gráfica digital abarca desde el análisis de la infraestructura utilizada (el tipo de cámara y configuración de la misma, tipo de escáner), los requisitos de la imagen (copia maestra / de uso), la preservación de los códigos EXIF e IPTC, hasta la calidad técnica de la imagen generada.

Mediante la aplicación de estos criterios cada imagen pasa por un proceso de valoración 
tras el cual se determina si es o no apta técnicamente. Las imágenes que no superen el estándar mínimo establecido, así como otros aspectos técnicos serán descartadas, aunque se conservarán como fuentes dcumentales.

El trabajo de campo sin embargo nos ha permitido concretar que no solamente los aspectos técnicos exigidos pueden ser la base del criterio de selección o eliminación de las imágenes presentadas por lo equipos. En algunas ocasiones, hay imágenes que, aún siendo desconsideradas desde el punto de vista técnico, se convierten en un material de indudable interés como fuente de información para el análisis y comprensión del registro inventariado.

Respecto a la imagen digital, los criterios establecidos por el área de técnicas gráficas, pueden dividirse en requisitos y configuración de la cámara, los requisitos mínimos para la Imagen Maestra y requisitos para la Copia de Uso.

Para el desarrollo del trabajo de campo, los equipos deben disponer de una cámara réflex digital, con una resolución mínima de ocho megapíxel y con formato de captura en raw (negativo digital) ${ }^{3}$. Por otro lado, los equipos deben entregar unos atributos mínimos o descriptores de cada imagen. Estos datos son relativos a la identificación (código y denominación del registro), localización (provincia, municipio), fecha de captura y nombre del autor. Ello permitirá asignar "metadatos" (datos sobre datos), garantizando la correcta ubicación de las imágenes en el banco de imágenes y su fácil recuperación.

Pero aún más importante que el conocimiento de estos requisitos y criterios técnicos, fáciles de adquirir y transmitir a los equipos, es el uso adecuado de las técnicas y herramientas para la documentación audiovisual, adaptadas a los objetivos, enfoques y criterios de la investigación y del método etnográfico. El entrenamiento necesario para ello no se adquiere de forma tan sencilla, sino a través de la experiencia y de la formación académica que debería ofrecerse en esta materia. Las deficiencias detectadas en este sentido, se han intentado resolver mediante la organización de jornadas de capacitación y cursos formativos específicos en el manejo de estas técnicas y herramientas.

Además de la fotografía digital, se han empleado otros soportes para completar la documentación de las expresiones culturales registradas. Las grabaciones sonoras o audiovisuales de entrevistas a informantes, músicas y sonidos, procesos de producción, rituales festivos, danzas, bailes, etc., o la digitalización de documentos (programas de fiestas, carteles, fotografías antiguas, estatutos de hermandades y cofradías, etc...) han permitido obtener una documentación susceptible de convertirse a su vez en Patrimonio Documental.

3. Las imágenes presentadas deben ser entregadas tanto en formato raw como en jpg. Las primeras debían contar con una resolución entre 240-300 pixeles por pulgadas (en adelante ppp), un código de color rgb , y un tamaño aproximadamente de 17 megabytes. Las copias deben ser entregas en jpg., con una resolución de setenta y dos ppp y un tamaño de cuatrocientos megapíxeles. 
Los complejos procesos de recogida, selección y gestión del material audiovisual, son un paso imprescindible en la documentación del patrimonio cultural inmaterial debido a la especificidad de estas expresiones, a su dinamismo y a las permanentes transformaciones, no solo del objeto de documentación sino también de las herramientas empleadas.

Aunque el proyecto del Atlas del Patrimonio Inmaterial de Andalucía aún no ha terminado y los equipos de trabajo continúan su labor de registro en el territorio, podemos señalar algunos objetivos para mejorar el proceso de documentación audiovisual a partir de la experiencia adquirida:

- Paliar el extrañamiento mostrado frente a las herramientas básicas de documentación audiovisual mejorando la formación de los especialistas en Antropología en estas técnicas.

- Necesidad de un criterio selectivo adecuado en la captura y entrega de las imágenes. Lo contrario, puede generar problemas de almacenamiento del material digital, y falta de criterio técnico y documental.

- Mejorar la formación en técnicas de captura de video y sonido, pues la falta de dominio de estas herramientas ha motivado una preferencia por el uso de la fotografía en detrimento de otros soportes.

Junto a estos aspectos, debemos señalar también que el proyecto del Atlas del Patrimonio Inmaterial de Andalucía, ha desarrollado varias propuestas metodológicas dirigidas a la difusión del mismo y a la importancia que tiene la documentación audiovisual en el registro de este tipo de bienes patrimoniales.

Las propuestas presentadas pueden dividirse en dos grandes bloques. Por un lado la elaboración de una serie documental centrada en los valores del patrimonio inmaterial de Andalucía y la diversidad de manifestaciones existentes, y por otro lado el desarrollo de microespacios que resuman brevemente algunas de las expresiones que definan por sus características a determinados territorios y respondan a las tipologías previamente establecidas desde el análisis de los resultados derivados del trabajo de campo.

Ambos modelos pretenden ser una reflexión sobre el patrimonio inmaterial de Andalucía, sus significados y funciones, su especificidad y capacidad de transformación y su relevancia como marcadores de identidad de colectivos que integran y definen territorios.

Este análisis de la realidad a través del patrimonio inmaterial y el uso de los medios audiovisuales, pretende además de contextualizar prácticas, saberes, procesos y conocimientos, articular mecanismos que incidan en el conocimiento de la diversidad cultural de Andalucía, distanciándose de los discursos y de las dinámicas homogeneizadoras. 
Para la preparación de las grabaciones ha sido imprescindible contar con el trabajo de campo previo, paso inicial para conocer todos y cada uno de los elementos significativos y relevantes de cada grabación. Realizado el registro y teniendo en cuenta las aportaciones de los investigadores y de los protagonistas, se han elaborado guiones con el objetivo de documentar audiovisualmente los ejemplos de patrimonio inmaterial seleccionados.

La mirada etnográfica y los objetivos previamente planteados otorgan por tanto al documento audiovisual un importante valor, como medio de salvaguarda y apoyo al registro. Las fotografías o los videos, más allá de ser imágenes fijas o en movimiento, forman parte de una metodología y un discurso donde deben reconocerse las expresiones y colectivos reflejados en el proyecto del Atlas del Patrimonio Inmaterial de Andalucía.

Teniendo en cuenta la especificidad de cada uno de los ámbitos tratados, el contexto en el que estos se desarrollan, la diversidad de tipologías y su relación con los colectivos que los reproducen, se han seleccionado para su grabación diferentes ejemplos, pretendiendo en todo momento cumplir con los objetivos del proyecto y la documentación aportada por los diferentes miembros del equipo de trabajo.

En este sentido, se han llevado a cabo diferentes grabaciones sobre rituales festivos, oficios, modos de expresión y alimentación. Respecto a los primeros, y ejemplo de la diversidad de manifestaciones festivo-ceremoniales que podemos encontrar en Andalucía, podemos señalar las Fiestas en honor al Cristo de la Yedra en Valor (Granada), el Viernes Santo en Alcalá la Real (Jaén), las Fiestas en honor a Santa Ana en Santa Ana la Real (Huelva), o la romería de Cuatrovitas en Bollullos de la Mitación (Sevilla). Sirvan también como ejemplo, las grabaciones del Encuentro de cuadrillas de ánimas en Vélez-Rubio (Almería), o la Danza de los Locos en Fuentecarreteros (Córdoba), ejemplos ambos donde podemos destacar la tradición oral y los mecanismos de transmisión de estas expresiones ${ }^{4}$.

El Atlas del Patrimonio Inmaterial de Andalucía se encuentra este año en su tercera fase

4. Junto a las anteriores grabaciones, también se ha documentado audiovisualmente la Elaboración de Cerámica en Alhabía (Almería), fiestas de laVirgen del Rosario en Castril (Granada), el trabajo de las salinas de interior en Prado del Rey (Cádiz), la romería de la Fuensanta de la Corcoya (Badolatosa, Sevilla), el Corpus en Carcabuey (Córdoba), las fiestas en honor a la Virgen de los Remedios en Campotéjar (Granada), la fiesta de San Francisco en Albánchez de Mágina (Jaén), el Auto de los Reyes Magos en el Viso (Córdoba), la fiesta de la Virgen de la Piedad en Baza (Granada), la elaboración de vidrio soplado en Castril (Granada), la Semana Santa y preparación del Huerto Niño en Pujerra (Málaga), la fiesta de la Virgen del Carmen en Grazalema (Cádiz), las Cruces de mayo en Almonaster la Real (Huelva), la Candelaria en Puebla de los Infantes (Sevilla), la fiesta de Moros y Cristianos en Campillo de Arenas (Jaén), el festival de Verdiales en Málaga (Málaga), la Cabalgata de Reyes Magos en Higuera de la Sierra (Huelva), la saca del Corcho en la sierra de Huelva, la Virgen del Carmen en Barbate (Cádiz), las fiestas de San Marcos en Ohanes (Almería), la fiesta de la Pascua (ánimas benditas) en Puebla de Don Fadrique (Granada), la Zambomba en Jerez de la Frontera (Cádiz), las fiestas de San Antón en Orce (Granada), la pesca del atún de almadraba en Conil (Cádiz), o las fiestas en honor a la Virgen de los Rondeles en Casarabonela (Málaga). 
de investigación, que se extenderá hasta el 2012. Es un proyecto que permanecerá vivo y abierto para poder representar con idéntico tratamiento y visibilizar, en la medida de lo posible, a todos los elementos culturales vivos y simbólicamente significativos con los que se identifican los colectivos sociales andaluces. 


\section{REFERENCIAS BIBLIOGRÁFICAS}

AGUDO TORRICO, J. (1999) "Arquitectura tradicional. Reflexiones sobre un patrimonio en peligro" en Revista PH, No 29, Sevilla. Pag. 183

AGUDO TORRICO, J (2000) "Romerías, ferias y fiestas. Significados y funciones de las fiestas andaluzas". En CANO GARCÍA (dir.) (2002) Conocer Andalucía: gran enciclopedia andaluza del siglo XXI. Sevilla: Tartessos, v. VI, pp. 256-303

AGUDO TORRICO, J (2003) Antropología y Patrimonio: Investigación, Documentación e Intervención. Granada: Junta de Andalucía.

AGUDO TORRICO, Juan y DELGADO MÉNDEZ, Aniceto (2011) "La tradición privatizada. Registro de propiedad y derechos colectivos". En Actas del XII Congreso Nacional de Antropología. León.

ARDEVOL, Elisenda (2006) La búsqueda de la mirada. Antropología visual y cine etnográfico. Barcelona: UOC.

BARTHES, Roland (2010) La cámara lúcida. Barcelona: Paidós (1980).

BELTING, Hans. (2007) Antropología de la imagen. Madrid: Katz.

BERGER, John. (2000). Modos de ver. Barcelona: Gustavo Gili.

BOURDIEU, P. (2003) Un arte medio. Ensayo sobre los usos sociales de la fotografía. Barcelona: Gustavo Gili.

CANO GARCÍA, G. (2000) "Una propuesta de comarcalización para Andalucía". En CANO GARCÍA (dir.) Conocer Andalucía: gran enciclopedia andaluza del siglo XXI. Sevilla: Tartessos, 2000-2002, v. X, pp. 10-86

CARRERA DÍAZ, G. (2009a) "Atlas del Patrimonio Inmaterial de Andalucía. Puntos de partida, objetivos y criterios metodológicos." Boletín del Instituto Andaluz del Patrimonio Histórico, $\mathrm{n}^{\circ}$ 71. Consejería de Cultura. Junta de Andalucía. Sevilla (pdf)

CARRERA DÍAZ, G. (2009b) "Iniciativas para la salvaguardia del Patrimonio Inmaterial en e contexto de la Convención UNESCO, 2003: una propuesta desde Andalucía" en MINISTERIO DE CULTURA Patrimonio Cultural de España, 0. El Patrimonio Inmaterial a Debate. Madrid. (pgs. 179-200) (pdf)

CARrerA DÍAZ, G. (2007) “Base de Datos de Actividades Etnológicas". Ph Cuadernos № 20. El Sistema de Información del Patrimonio Histórico e Andalucía (Sipha). Sevilla, España. Instituto Andaluz de Patrimonio Histórico. Vol. 1. 2007. Pag. 108-133. ISBN: 84-8266-637-1 (pdf) 
CARRERA DÍAZ, G. (2006) “Itinerarios y rutas culturales en la web del IAPH”. PH Boletín del Instituto Andaluz del Patrimonio Histórico, no 57, febrero 2006, pp. 6-28. Consejería de Cultura. Junta de Andalucía. Sevilla. (pdf)

CARRERA DÍAZ, G. (2005) La Evolución del Patrimonio (Inter)Cultural: Políticas Culturales para la Diversidad. Patrimonio Inmaterial y Gestión de la Diversidad. Sevilla: Consejería de Cultura de la Junta de Andalucía. 2006. pp. 14-29 (pdf)

CARRERA DÍAZ Gema y DIETZ, Gunther (2005) Patrimonio Inmaterial y Gestión de la Diversidad. Sevilla. (pdf)

CARRERA DÍAZ, G., MONDÉJAR FERNÁNDEZ DE QUINCOCES, P. y SORO CAÑAS, S. (2007a) "La información del Patrimonio Inmueble". PH Cuadernos № 20. El Sistema de Información del Patrimonio Histórico e Andalucía (Sipha). Sevilla, España. Instituto Andaluz de Patrimonio Histórico. Vol. 1. 2007, pp. 108-133. (pdf)

CARRERA DÍAZ, G., MONDÉJAR FERNÁNDEZ DE QUINCOCES, P. y SORO CAÑAS, S. (2007b) "Base de Datos del Patrimonio Inmueble". PH Cuadernos No 20. El Sistema de Información del Patrimonio Histórico e Andalucía (Sipha). Sevilla, España. Instituto Andaluz de Patrimonio Histórico. Vol. 1. 2007, pp. 90-105.

CONSEJERÍA DE CUlTURA (1993) Plan General de Bienes Culturales. Consejería de Cultura y Medio Ambiente. Cádiz: Junta de Andalucía.

CONSEJERÍA DE CUlTURA (1997) Plan General de Bienes Culturales de Andalucía, 1996-2000. Documento de Avance. Consejería de Cultura, Junta de Andalucía. 1997.

CONSEJERÍA DE CULTURA (2007) Ley 14/2007 de 26 de noviembre de Patrimonio Histórico Andaluz. Junta de Andalucía. Consejería de Cultura de la Junta de Andalucía. 2005.

COTE MONTES, Eva (2011) “La cultura del olivar en Sierra Mágina”. Boletín del Instituto Andaluz del Patrimonio Histórico ${ }^{\circ}{ }^{79}$. Sevilla: Consejería de Cultura de la Junta de Andalucía.

DELGADO MÉNDEZ, Aniceto (2011) "Las danzas rituales en Andalucía. Contextos para la tradición” En Actas del XII Congreso Nacional de Antropología. León.

FLORIDO DEL CORRAL, David (2011) "La actividad de la pesca en el Campo de Gibraltar: del modelo intensivo al artesanal". Boletín del Instituto Andaluz del Patrimonio Histórico no 80. Sevilla: Consejería de Cultura de la Junta de Andalucía

FREUND, Gisela. (2008) La fotografía como documento social. Barcelona: Gustavo Gili.

GÓMEZ ARAGÓN, Anhjara (2011) "Estudio previo al registro en el Atlas del Patrimonio Inmaterial”. Boletín del Instituto Andaluz del Patrimonio Histórico no 80. Sevilla: Consejería de Cultura de la Junta de Andalucía 
LABORATORIO DE CARTOGRAFÍA E IMAGEN DIGITAL (2011): "Recomendaciones técnicas sobre la georreferenciación de entidades patrimoniales"

LABORATORIO DE CARTOGRAFÍA E IMAGEN DIGITAL

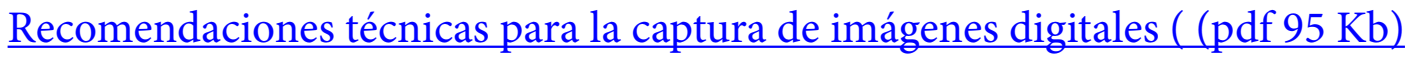

$\underline{\text { Recomendaciones técnicas para el tratamiento de imágenes digitales }}$

Recomendaciones técnicas para la metadación de imágenes (pdf $611 \mathrm{~Kb}$ )

LÓPEZ GALÁN, Juan Salvador (2011) “Semana Santa en el Bajo Almanzora: Huércal Overa, Cuevas del Almanzora y Turre". Boletín del Instituto Andaluz del Patrimonio Histórico n 79. Sevilla: Consejería de Cultura de la Junta de Andalucía.

MORENO NAVARRO, Isidoro (2000) “La identidad andaluza”. Enn CANO GARCÍA (dir) Conocer Andalucía: Gran enciclopedia andaluza del siglo XXI. SevillaTaretessos, 2000-2002. 10 vol, pp. 13-56.

ORTIZ GARCÍA, Carmen; SÁNCHEZ-CARRETERO, Cristina y CEA GUTIÉRREZ, Antonio (coords.) (2005) Maneras de mirar. Lecturas antropológicas de la fotografía. Madrid: CSIC.

RODRIGO CÁMARA, J. M. y DÍAZ IGLESIAS, J. M. (2011) "La representación cartográfica del paisaje cultural y el patrimonio inmaterial”. En ACOSTA BONO, G.; CORTÉS, José y FAJARDO DE LA FUENTE, A. (coords) La Cartografía: entre el documento histórico y la gestión del patrimonio". Revista PH Monográfico. Instituto Andaluz del Patrimonio Histórico. Junta de Andalucía. Sevilla, pp. 120-123.

UNESCO (1989) Recomendaciones para la Salvaguardia de la Cultura Tradicional y Popular.

UNESCO (1998) Informes sobre los criterios específicos para seleccionar los espacios culturales o formas de expresión cultural merecedores de que la UNESCO los proclame obras maestras del patrimonio oral e inmaterial de la Humanidad.

UNESCO (2003) Convención para la Salvaguardia del Patrimonio Cultural Inmaterial. París: UNESCO.

UNESCO (2006) Reunión de expertos sobre la participación de las comunidades en la Salvaguardia del Patrimonio Cultural Inmaterial. Tokio: UNESCO. 